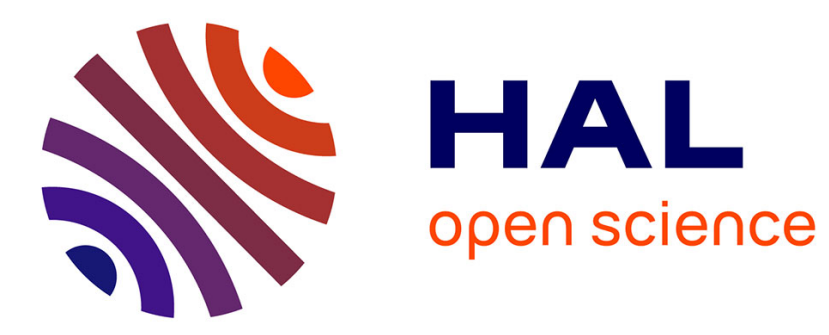

\title{
Nostalgia in online brand communities
}

Clara Koetz, John Daniel Tankersley

\section{- To cite this version:}

Clara Koetz, John Daniel Tankersley. Nostalgia in online brand communities. Journal of Business Strategy, 2016, 37 (3), pp. 22-29. 10.1108/JBS-03-2015-0025 . hal-01343206

\section{HAL Id: hal-01343206 https://hal.science/hal-01343206}

Submitted on 7 Jul 2016

HAL is a multi-disciplinary open access archive for the deposit and dissemination of scientific research documents, whether they are published or not. The documents may come from teaching and research institutions in France or abroad, or from public or private research centers.
L'archive ouverte pluridisciplinaire HAL, est destinée au dépôt et à la diffusion de documents scientifiques de niveau recherche, publiés ou non, émanant des établissements d'enseignement et de recherche français ou étrangers, des laboratoires publics ou privés. 


\section{NOSTALGIA IN ONLINE BRAND COMMUNITIES}

\section{Clara Koetz and John Daniel Tankersley}

\section{Introduction}

Social media has changed peoples' lives in several ways, and these changes can be particularly important from a consumer behavior standpoint. In social media websites, such as Facebook, consumers can easily create and join online brand communities to share common interests, values and experiences about products and brands. The resources shared in these communities may be material, cognitive and emotional. Furthermore, as with traditional brand communities, online communities are based on the creation and negotiation of meaning, which is related to the symbolic characteristics of products, brands and relationships (McAlexander et al., 2002). For example, a consumer may join a brand community not just because of their interest in the brand, but also because membership of this group makes them feel more interesting, young or similar, in terms of identity, to a specific group. These communities may be the scenario for the development of a unique subculture of consumption, in which people engage in activities and relationships, accepting some formal and informal rules, defining rituals and jargons, and building common beliefs and values.

In some situations, individuals organize themselves in communities around a nostalgic product, which has a similar meaning for a group of people. Nostalgic products may have a cognitive aspect, referring to memories associated with key moments or someone's youth, and an affective component, which connects these memories with affective experiences lived in past times (Holbrook and Schindler, 2003). That is, individuals can associate specific objects with events from their past that were, for some reason, significant in terms of emotions. The use or possession of these objects, many years later, is a way to reconnect with these events and an opportunity to revive the same emotions. When nostalgia characterizes a collective experience, in which the same object has a similar meaning and develops nostalgic feelings within a group of people, it may positively affect the development of social bonds, strengthening the links among members and perpetuating the community (Wildschut et al., 2014). We propose that nostalgia may be one of the core dimensions that stimulate consumers to participate in online brand communities. Specifically, this dimension is stimulated by the desire of being part of a group and expressed by the cognitive and emotional connections that consumers develop between a product or brand as a symbol of a specific past event or period.

Although several studies have examined subcultures of consumption (e.g., Shouten and McAlexander, 1995) and brand communities (McAlexander et al., 2002) in traditional contexts, relatively little has been written about the specificities of such groups in social networks. Similarly, there is a lack of studies examining nostalgia in online brand communities. This research aims to fill these gaps, exploring aspects related to consumption as a way of transmitting symbolic meaning, as well as expressing nostalgic feelings, in an online brand community. Thus, our objectives in the research are twofold. Firstly, we analyze the characteristics of a subculture of consumption developed in a brand community in social media. Secondly, we examine 
the role of nostalgic feelings in this community. For that, we conduct a netnographic study to examine the case of Caloi 10 in Facebook.

\section{Brand Communities in Social Media}

The need to live in groups and stablish social relationships is inherent to human beings. In some cases, individuals express this need by joining a brand community, in which the bonding component is the use or consumption of a specific product or brand. A brand community is "a specialized, non-geographically bound community, based on a structured set of social relations among admirers of a brand (Muniz and O'Guinn, 2001). McAlexander and colleagues (2002) showed that the expectation of being part of a group may be the main reason why someone acquires a product, as well as an exit barrier that prevents them from stopping buying it. That is, the social relationships developed in the group, and not the product itself, may be the main motive for the purchase of the product.

Subcultures of consumption arise from the desire of people to identify themselves with some specific products and brands and establish meaningful relationships. A uniform consumption pattern is promoted by a common ethos, a set of common values and rules that permeate the group's organization. The structure of the subculture, as well as the role of each individual in the group, is based on the commitment of individuals to these values and rules. For example, in an analysis of the subculture of consumption of Harley Davidson, Schouten and McAlexander (1995) identified a complex and hierarchical social structure that reflected different levels of participant status as a function of their commitment with the core values of the group, which were based on personal freedom, patriotism and machismo (manliness).

Although brand communities have been examined in different contexts and in relation to several products, only recently researchers have started to examine the similarities and specificities of these groups in social media. Just as in traditional contexts, online brand communities constitute a space where customers share content, meaning and values related to a specific brand or product. However, the technological aspects of Web 2.0 provide social media platforms with some possibilities, such as instantaneous, real-time communication on a global scale and in different formats (e.g., text, pictures and videos), that go way beyond traditional means of communication. Moreover, the logic of communication has been changing in these settings. In social media, consumers do not only absorb content produced or edited by someone else, but they also positively participate in creating, sharing and consuming content (Habibi et al., 2014). The content created by users (user-generated content, UGC) gives a completely new dimension to social media in terms of knowledge production and socialization, which has important repercussions for consumer culture and brand communities.

The unique characteristics of social media have stimulated companies to invest more and more in online brand communities for several reasons, such as building awareness and image, getting feedback from consumers and involving them in cocreation processes and generating revenues. The effectiveness of these activities has also been documented by some preliminary studies, which show that participation in online communities can create value for companies in several ways. For example, Park and Kim (2014) conducted a study of brand pages of apparel and restaurants/coffee houses on Facebook, showing that the customers' participation in an online brand community has a positive effect on brand relationship quality and on the willingness to 
spread good words about the brand. Similarly, Hutter, Hautz, Denhardt and Fuller (2013) demonstrated that the engagement of consumers in a car manufacturer fan page on Facebook had a positive effect on their brand awareness, word of mouth and purchase intention.

\section{Nostalgia}

Nostalgia refers to the desire of some individuals to collect possessions, or develop activities, that were more common, or somehow associated, with past events. Although some early studies used to identify nostalgia as a pathological disease (such as a mentally compulsive disorder, Fodor, 1950, p. 25), usually associated with negative affective states, recent evidence has shown that nostalgic feelings are predominantly positive, and that they might even lead to important psychological benefits, such as positive self-esteem (Vess et al., 2012) and optimism (Cheung et al., 2013). In this article, we adopt the concept of nostalgia proposed by Holbrook and Schindler (1991, p. 330) as "a preference (general liking, positive attitude, or favorable affect) toward objects (people, places, or things) that were more common (popular, fashionable, or widely circulated) when one was younger (in early adulthood, in adolescence, in childhood, or even before birth)".

Nostalgia has been studied from an individual and a social perspective.

Regarding the former, objects from the past, or that remind someone of past events, may be used as a connector with pleasant and happy past experiences. Thus, nostalgia refers mainly to objects related to past events that have been lost, because for some reason they have become difficult to obtain or because the consumer has no longer access to them (Holbrook and Schindler, 2003). For example, the preference for a specific perfume does not necessarily lead to a nostalgic emotion. But a perfume that was worn during a specific period of life, such as someone's youth, and that brings back memories associated with that period, usually does. These objects, such as products, pictures and souvenirs, can characterize symbolic elements with meaningful life associations that individuals use to define their independent selves and express their identities (Belk, 1990).

Furthermore, nostalgia may be connected with a collective experience and promote social well-being, such as increasing the perception of social support and reducing the feeling of loneliness (Zhou et al., 2008). In this regard, individuals may consume nostalgic products as a way of reviving past group experiences or events that were significant in their lives, and reconnecting with social communities that used to consume these products together. That is, the feeling of nostalgia, when exercised in a collective way, can positively affect individuals not only at a private level, but also to stimulate a sense of belonging and self-support among participants of a group (Wildschut et al., 2014). On the basis of this social dimension, we consider that nostalgia may be a bonding component in brand communities, increasing the interest of participants in joining and perpetuating the group, which can be especially relevant in social media platforms.

\section{Method}

A netnographic study was conducted in the Caloi 10 Official Group on Facebook, from April to October 2013. Caloi 10 is a Brazilian bicycle brand that was launched in 1972 and became a cultural landmark in Brazil. The choice of this product 
was motivated by the nostalgic characteristics of this brand, as well as the importance that such a bicycle model has acquired in the Brazilian market. Moreover, this group presents important requirements necessary for a netnographic research with relevant content - ideal number of members, representing several social classes and regions of the country, interactions in large quantity and information exchanges with relevant content.

The procedures for data collection and analysis were conducted in three ways: (1) Communications: All interactions (postings) of the group, in different formats (texts, videos and pictures) were copied and saved daily. 2) Memos (notes of observations) such as field notes, with interpretations of implicit contexts in interactions were registered. 3) Interviews: Three semi-structured interviews were conducted with group members, who were chosen due to their higher involvement with the group (one of the interviewees was the group founder and administrator). The interviews were conducted in October 2013, via telephone, lasting about 20 minutes each. At the end of the data collection, a total of 230 double-spaced, ten-point type pages were generated with the transcription of the interactions and memos.

\section{Results}

Data analysis was conducted using Dedoose software. This software was developed by Sociocultural Research Consultants (SCRC) to analyze qualitative and mixed methods research in various formats. Four categories emerged from the analysis: (1) Identity and nostalgia (2) Hierarchical social structure (3) the Subculture's ethos (3) and (4) Consumption habits.

\section{a. Identity and Nostalgia}

The results showed that nostalgia is a determinant factor in motivating members to have a Caloi 10, as well as to join the brand community. Respondents clearly showed their passion for cycling, and the nostalgic feelings associated to this specific model of bicycle were identified by the use of terms such as restoration, time, antique, etc. We observed that their passion for the brand originates in childhood, and that this product represents an object through which they can express their identity. In some cases, the bicycle has been owned by an older brother or relative, and was considered to be a desired product. More than an individual meaning, it was a reference for a generation of consumers, and has been influencing even younger people.

In accordance with the social dimension of nostalgia, participants showed a collective connection with Caloi 10, based on the symbolic meaning of this bicycle for them. The community represents a way of manifesting their passion for cycling and for Caloi 10, as well as an opportunity to show to other people their involvement with the brand. All participants share the same positive feelings for Caloi 10, and these feelings seem to be the bonding element that keeps the group together. That is, the product not only leads to nostalgic emotions that strengthen the links between participants and the brand, but it also binds participants to each other, stimulating a sense of a community.

The following extract exemplifies the feeling of collective nostalgia present in the group: 
“...the bike is from the 60's, and one can feel the spirit and soul of such things that bring good memories of times that marked our lives...of things that move us and make us keep a cyclist's soul...”

\section{b. Hierarchical Social Structure}

The hierarchical social structure of Caloi 10 demonstrated that the position of each participant is determined by his/her commitment to the values of the bicycle and to the group, which must be recognized and legitimised by other members. Thus, those who exert the position of "leaders", in the top of the hierarchy, have constituted a strong social capital based on a deep knowledge about the technical characteristics and the history of the product, as well as a high level of involvement in the community. At an intermediate level, there are participants who follow the leaders and are accepted by others as group members, but do not have the same status of the first group. Finally, on the periphery, there are beginners and fans, who show a low level of interaction with other members and are only starting to be recognized as participants by the group.

Rising up through this hierarchy also has an impact on the identity of the group members. Adherence to the values and rules of the community constitutes a type of "acculturation" process, in which individuals influence and are influenced by the group. This process is based on the higher level of identification that members demonstrate with the values of the community over time, and with the recognition of the leaders as a reference that must be respected and followed. Thus, the higher the position in the hierarchy, the more the individuals will be used to the ideas, values, jargons and activities of the group.

\section{c. Ethos}

Ethos comprises the beliefs and values of the community from a social and cultural point of view. The ethos of the Caloi 10 official community is formed by common interests and tastes among members, which are not necessarily related to specific behaviors or attitudes, as well as by more aspirational aspects, such as a feeling of goodwill that members manifest towards each other. That is, it reflects a shared conscience among the members that is essential for the existence of the community. The ethos also comprises the community's value judgment, which is defined by the members themselves. For example, when a comment or any topic that is inconsistent with the community's values and beliefs is posted, the members organically disqualify it, which perpetuates the ethos and grants the community its legitimacy.

The results showed clear differences between the ethos of the three levels of the community's hierarchical social structure. Members with lower commitment to the brand (beginners, fans and followers) are more likely to criticize or make negative comments about the brand at any time, despite being involved with the community and having great admiration for Caloi 10. Followers are members that have some degree of identification with the subculture, but do not have some of the basic requirements to reach the higher level in the hierarchy. Leaders showed a higher degree of commitment with the product, always defending it and never criticizing it. They correspond to the group more intensively immersed in the subculture of consumption and this affects their lifestyles, behavior and choices. Thus, aspects such as complete adhesion to the group, strong emotional connections and a high level of satisfaction with the product are common values that compose the ethos of leader members. 
The following extract of interactions between a follower and a leader exemplify these differences:

Follower: "...Caloi should make improvements in the product...because of a well-known and well respected brand product's grotesque failure that unfortunately put his life at risk, and can also put other people lives at risk causing a very serious accident if nothing is done..."

Leader: "It's important to have tips about security, but this case has already been discussed and solved, so I don't see the point of talking about this over and over again. Here in the group everyone is sure about the quality of Caloi 10”.

\section{d. Consumption Habits}

This category is based on cultural aspects experienced by group members and on the social aspects of their relationships. Group members are always aspiring to a higher position in the hierarchy. They involve themselves in activities such as helping and giving advice to each other on several subjects, such as where to find parts that are no longer manufactured and how to solve problems related to the product. Members are involved in sharing their knowledge about the product with other members, which contributes to the expression of their identification with the brand, and at the same time raises their position in the hierarchy.

"This is a place where we can talk about what we like most, Caloi 10, exchange ideas, get parts that are no longer manufactured, and more importantly, get to know people who share the same passion..."

\section{Discussion and Managerial Implications}

Social media's unique technological characteristics allow consumers to create and exchange content about products and brands as they have never had the opportunity to do before. Moreover, on these platforms, they are able to develop a sense of community, based on the creation of strong social ties and characterized by specific values, structure and consumption habits. In this study, we showed that this sense of community may be based on a collective nostalgic product, the Caloi 10 model of bicycle. Nostalgia constitutes a predominantly positive emotion that may reinforce the bonds between individuals and a product, or brand, as well as between members of a group among each other. Thus, this study corroborates the idea suggested by Wildschut and colleagues (2014) that nostalgia consists in a collective emotion that may confer several positive benefits to the group.

Our results offer valuable guidelines to companies with regards to consumer behavior in social media. Firstly, they clarify the importance of understanding and developing a brand from a social perspective. The relationship between consumers and products may be based on a collective vision, in which the product represents the same set of values and a unique identity for a group of consumers. In this case, the development of positive emotions toward the brand, such as the case of nostalgic emotions, may constitute a powerful connector, that not only intensifies the relationship between individuals and the brand, but also that of individuals with each other. Of course, it is not an easy task for a company to transform its product in an icon for a whole generation, as is the case of Caloi 10. However, nostalgic feelings may be 
boosted not only in relation to a company's classic product, but also towards a specific past event, idea or behavior (e.g., a film, music or fashion). Moreover, social media has the potential to help in creating a strong collective identity even for brands that are apparently less appealing.

Our results also demonstrate the importance of understanding the social hierarchical structure of online brand communities, and more specifically, of respecting the psychological mechanisms of influence existing among participants in these groups. The role of the individuals in leadership positions is without a doubt strategic from a marketing perspective, as they affect not only the behavior and attitudes towards the product, but also influence the collective identity of the brand. Moreover, our results showed that participants in a brand community may influence each other identities, lifestyles and choices.

For companies, it is essential to follow these communities, understanding the psychological processes underlying the social interactions and adapting marketing activities to positively influence consumer behavior towards the brand. However, a word of warning should be given regarding the level of participation of marketers in social media. Although an online brand community offers a perfect environment for the development of several activities (such as events, contests and customer relationship activities), companies cannot forget that this is the "customers space", and that they define the rules and are in control in their communities. This can appear just a detail, but it completely changes the effectiveness of the activities in this context.

We conclude that as in traditional settings, subcultures of consumption organized in social media are also hierarchical social structures, whose members share specific values, beliefs, feelings and behavior. Nostalgia characterizes an important dimension in this community, positively affecting the relationship between individuals and the brand. Moreover, nostalgic feelings were shown to be a bonding element that keep people together and perpetuate the existence of the community. The results demonstrate that the values and beliefs identified in the community are not only inherent in the development of the group subculture, but also contribute to the process of forming the identity of each group member.

\section{References}

Belk, R. W. (1990), "The role of possessions in constructing and maintaining a sense of past", in Goldberg, M., Gorn, G and Pollay, R. (Eds.), Advances in Consumer Research, Provo, UT: Association for Consumer Research, Vol. 17, pp. 669-676.

Cheung, W. Y., Wildschut, T., Sedikides, C., Hepper, E. G., Arndt, J. \& Vingerhoets, A. J. J. M. (2013), "Back to the future: Nostalgia increases optimism", Personality and Social Psychology Bulletin, Vol. 39, No. 11, pp. 1484-1496.

Fodor, N. (1950), "Varieties of nostalgia", The Psycho-Analytic Review: An Educational American Journal of Psychoanalysis, Vol. 37, pp. 25-38.

Habibi, M. R., Laroche, M. \& Richard, M. O. (2014), "Brand communities based in social media: How unique are they? Evidence from two exemplary brand communities", International Journal of Information Management, Vol. 34, No. 2, pp. 123-132.

Hutter, K., Hautz, J., Dennhardt, S. \& Fuller, J. (2013), "The impact of user interactions in social media on brand awareness and purchase intention: The case of MINI on Facebook", Journal of Product \& Brand Management, Vol. 22, No. 5/6, pp. 342-351. 
Holbrook, M. B. \& Schindler, R. M. (1991), "Echoes of the dear departed past: Some work in progress on nostalgia", in Holman, R. H. and Solomon. M. R. (Eds.), Advances in Consumer Research, Provo, UT: Association for Consumer Research, Vol. 18, pp. 330-333.

Holbrook, M. B. \& Schindler, R. M. (2003), "Nostalgic bonding: Exploring the role of nostalgia in the consumption experience", Journal of Consumer Behaviour, Vol. 3, No. 2, pp. 107-127.

McAlexander H. J., Schouten, W. J. \& Koening, H. F. (2002), "Building brand community", Journal of Marketing, Vol. 66, No. 1, pp. 38-54.

Muniz Jr., A. M. \& O'Guinn, T. C. (2001), "Brand community", Journal of Consumer Research, Vol. 27, No. 4, pp. 412-432.

Park, H. \& Kim, Y. K. (2014), "The role of social network websites in the consumerbrand relationship", Journal of Retailing and Consumer Services, Vol. 21, No. 4, pp. 460-467.

Schouten, W. J. \& McAlexander H. J. (1995), "Subcultures of Consumption. An Ethnography of The New Bikers", Journal of Consumer Research, Vol. 22, No. 3, pp. 43-61.

Vess, M., Arndt, J., Routlege, C., Sedikides, C. \& Wildschut, T. (2012), "Nostalgia as resource for the self", Self and Identity, Vol. 11, pp. 273-284.

Wildschut, T., Bruder, M., Robertson, S., Tilburg, W. \& Deidikides, C. (2014), "Collective nostalgia: A group-level emotion that confers unique benefits on the group", Journal of Personality and Social Psychology, Vol. 107, No. 5, pp. 844-863.

Zhou, X., Sedikides, C., Wildschut, T. \& Gao, D. G. (2008), "Counteracting loneliness. On the restorative function of nostalgia", Psychological Science, Vol. 19, No. 10, pp. 1023-1029.

\section{About the authors}

Clara Koetz is an Assistant Professor at ESC Rennes School of Business, France. She holds a PhD in Business Administration from University of Rennes 1, France, in double degree with Federal University of Rio Grande do Sul, Brazil. Her research interests include online consumer behavior, affect and consumer information processing. Clara Koetz is the corresponding author and can be contacted at: clara.koetz@esc-rennes.com

John Daniel Tankersley holds a master's degree in Business Administration from University of Santa Cruz do Sul, Brazil. He works as a Marketing Consultant creating and implementing marketing strategies for a number of companies. His areas of expertise include online consumer behavior and digital marketing. John Daniel Tankersley can be contacted at: john@gandapropaganda.com.br 